\title{
Correction to: Dietary potassium restriction attenuates urinary sodium wasting in the generalized form of pseudohypoaldosteronism type 1
}

\author{
Masanori Adachi ${ }^{1}$ (1) $\cdot$ Toshihiro Tajima $^{2} \cdot$ Koji Muroya $^{1}$
}

Published online: 29 April 2020

(c) Japanese Society of Nephrology 2020

\section{Correction to: CEN Case Reports (2020) 9:133-137 https://doi.org/10.1007/s13730-019-00441-0}

In the original publication of the article, there are two minor errors in Fig. 2 and these include one missing arrow in Fig. 2d and appears as an incorrectly drawn solid lines as dashed line in Fig. 2d. The corrected figure is given below.
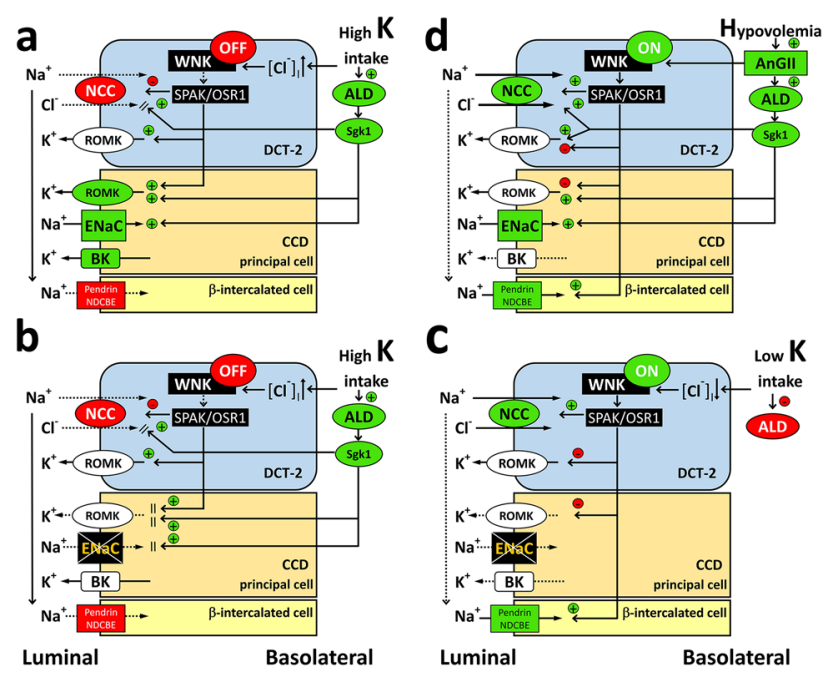

Publisher's Note Springer Nature remains neutral with regard to jurisdictional claims in published maps and institutional affiliations.

The original article can be found online at https://doi.org/10.1007/ s13730-019-00441-0.

Masanori Adachi

madachi@mars.sannet.ne.jp

1 Department of Endocrinology and Metabolism, Kanagawa Children's Medical Center, Mutsukawa, 2-138-4,

Minami-ku, Yokohama 232-8555, Japan

2 Department of Pediatrics, Jichi Children's Hospital Medical Center Tochigi, Tochigi, Japan 